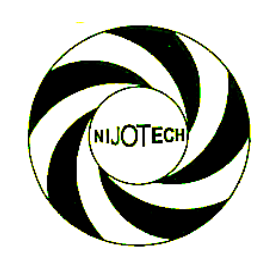

Nigerian Journal of Technology (NIJOTECH)

Vol. 37, No. 4, October 2018, pp. 1039 - 1048

Copyright@ Faculty of Engineering, University of Nigeria, Nsukka,

Print ISSN: 0331-8443, Electronic ISSN: 2467-8821

www.nijotech.com

http://dx.doi.org/10.4314/njt.v37i4.25

\title{
IMPROVED LEAVE SCHEDULING ALGORITHM FOR IMPROVED SERVICE DELIVERY IN THE NIGERIAN UNIVERSITY SYSTEM
}

\author{
B. U. Stephen ${ }^{1,}$, G. A. Chukwudebe ${ }^{2}$, D. O. Dike ${ }^{3}$ and N. Chukwuchekwa ${ }^{4}$

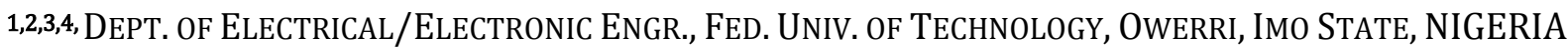 \\ E-mail addresses: ${ }^{1}$ blissustephen@gmail.com, ${ }^{2}$ chukwudebe.gloria@gmail.com, \\ ${ }^{3}$ damian.dike@futo.edu.ng, ${ }^{4}$ nkwachukwu.ng.n@ieee.org
}

\begin{abstract}
This work presents a leave management solution where leave requests by University academic staff are processed with service delivery centered yardsticks like staff mix by rank and lecturer-to-student ratio. This leave management solution is intended to interface with a staff database, course registration system and a staff appraisal system. In working mechanism, it is an algorithm that assesses leave requests and schedules the leave requested for periods having least impact on staff mix by rank and lecturer-to-students ratio. In the Nigerian university system, leave can be managed to avail academic staff for training, research and even rest. In pursuance of these, human resource planners may overcommit staff to it, leaving the system understaffed at key moments, or under commit to it and lose out on the benefits. Either way, service delivery is adversely affected. The algorithm was developed following iterative incremental process model, in three increments, each executing their corresponding set of requirements. The algorithm was implemented using MATLAB. The work features generation of sample data of academic staff in a particular engineering degree program, sorting of that data into staff mix by rank, and then computation of available and recommended staff mix by rank given the number of students the engineering program has. The algorithm schedules leave for periods of least impact on service delivery of University academic staff by picking the year with the least shortfall in available staff mix considering the recommended staff mix.
\end{abstract}

\section{Keywords:-Staff mix by rank, Leave management, Lecturer-to-students ratio, Human Resource Planning}

\section{INTRODUCTION}

In improving lecturers' service delivery in the University system, lecturers embark on training and research programmes. Often, they are relieved of teaching and administrative duties to enable them focus on such programmes for the duration of the study or research programmes. The effect of this momentary reduction in staff strength is that remaining lecturers take on more courses than approved and class sizes increase beyond what is recommended per lecturer by National University Commission (NUC), a body responsible for regulating university programmes in Nigeria. In some other cases where staff-mix by rank is distorted, either some lecturers get assigned to teach or supervise students meant for lecturers of superior ranks, or such students are not taught or supervised at all. Faced with this, Management of Universities resort to assessing staff leave requests based purely on number of staff available and those on leave, ignoring more encompassing criteria like lecturer-to-student ratio, lecturer-to-course ratio, approved staff mix by rank and the stipulations in staff conditions of service. In the end, advantages of manpower training and development (in the case of study leave), employee satisfaction (in the case of sabbatical leave for instance) and research advancement (in the case of research leave) are traded off. There is, therefore, the need to position the leave management system to maintain service delivery on all fronts.

A good Human Resource Planning (HRP) process should enable an organization to identify the level and the quality of human resources required to meet its business objectives [1]. Exactly what staff mix by rank would be manageable for a leave request to be granted? Which period would be low-risk, when a particular leave request can best be referred to? The personnel management section of a school's Human Resource Management System should play a key role in facilitating and advising heads of sections or divisions in identifying implications of decisions made on leave 
requests. In this regard, leave requests need not go for upper management decision when there is a chance it would be denied. Heads of departments, Faculty deans etc. should be equipped with advisory tools for such decisions.

In this paper, an algorithm to assess leave requests and determine best periods to grant them was modeled. The deciding factors for the algorithm are approved lecturer-to-student ratio and academic staff mix by rank, specifically, those approved for engineering programs in Nigeria by the NUC. The algorithm will take into consideration staff promotion i.e. the fact that the rank of staff seeking leave might not be same over the period of wait/computation (i.e. the period staff seeking leave has to wait till when leave sought for is best for approval). Academic staff mix by rank and the Lecturer-to-students ratios are not the same across all degree programmes. Recommended lecturer-tostudents ratio for this work's program of concern, Engineering, is 1:15. Lecturer-to-students ratio is computed by dividing total number of students in a particular degree program by the available number of lecturers in that program [2].

As stated in the first paragraph, allowing some academic staff on leave reduces staff number and changes number of staff per rank. These two aspects directly impacts on number of students taught by a lecturer (i.e. lecturer-to-student ratio) and staff mix by rank respectively. This is why lecturer-to-student ratio and staff-mix by rank were chosen as service delivery yardsticks to base the leave management algorithm developed in this work. The major contribution of this work is to provide university management with a tool to make more informed decision on leave requests. By basing the algorithm in this work on service delivery factors, university human resource (HR) planners would be rest assured that study and research leaves are granted without unduly sacrificing teaching effectiveness or lectures.

\section{RELATED WORKS}

A mathematical model is formulated in [2] for determination of recommended number of academic staff in the three categories (from Lecturer I downwards, Senior Lecturers and Professors/Readers) for each degree programme using as variables total number of students in the degree programme, number of academic staff ranked Lecturer I and below required and number available; number of Senior lecturers required and number available; and number of Professors/Readers required and number available. The work offers simplified mathematical formulas for determination of the number of academic staff ideal for each category of academic staff mix, given a certain of students in any programme/course of interest.

The work in [3] was aimed at answering two main questions: how can the mobility management of human resources under constraints within enterprise be optimized? How can the impact of the HR mobility on performance and productivity be quantified? The work evaluated the productivity effect of moving some staff from one site to another, and moving others in as replacement. To answer the aforementioned questions, it was of interest to formalize a Constrained Mobility Management of Human Resources such as the HR redeployment and the HR recruitment principally within a multi-sites enterprise. The work's approach describes the models and methods for a rule-based expert system to optimize the redeployment procedure (reassignment) and the recruitment procedure of HR. The work also presents mathematical models for HR mobility management and HR recruitment. The aspects of mobility management considered were recruitment and redeployment. There are areas of improvement in the work under review. First, in redeployment, problems induced by staff shortfall can easily be solved by bringing on replacements from other sites/units. But in leave/vacation management, University Managements are hoping to avoid needing replacements when some academic staff go on leave. This makes leave/vacation aspect of mobility management of more concern to universities. Secondly, the productivity or service delivery yardsticks considered in evaluated HR mobility in the work under review will not really suit mobility management of academic staff in a University system. Thirdly, the mobility management system in the work considers ideal workforce. In considering the Nigerian University system where ideal workforce, for example ideal staffmix by rank, is hard to come by, some other approach is needed.

In [4] is a leave management algorithm for academic staff in Nigerian universities. It is a service delivery centred leave management solution in that it schedules leave for periods when there is the least difference between the number of staff available and the number of staff recommended for the staff category which the staff seeking leave belongs. However, the limitation of this algorithm is that it does comparison of the differences for the same staff category all through the projection period. It limits the accuracy of the leave period recommendation in that the rank of staff seeking leave may not remain constant during the projection period. 


\section{METHODOLOGY}

Previously, leave requests of academic staff in Nigerian Universities had been evaluated solely on number of staff available. In some cases, leave approvals are capped off at the same number for different degree programs despite dissimilarity in student population and recommended lecturer-to-students ratio. What this portends is that some programs which are otherwise healthy enough for more leave approvals are denied while some understaffed programs are plunged into deeper staff deficit because they are yet to exceed their leave quota.

For clarity hereon, it is important to state that in the Nigerian university system, there are seven ranks of academic staff as shown in Table 1. NUC has structured these ranks into three categories of academic staff mix: Lecturer I downwards (made up of Graduate Assistants, Assistant Lecturers, Lecturer II and Lecturer I), Senior Lecturers and Professors/Readers for a given degree programme. As would be seen later, these academic staff mix also have recommended percentages.

The solution presented in this work is one that evaluates leave requests based on the negative impact it will have on the specific staff mix category to which the staff seeking leave belongs. This impact will be measured by the shortfall of the available staff mix from the recommended staff mix. It does this year by year until the projection-limit year. The shortfall i.e. difference of the available staff mix from the recommended staff mix for each of the years are compared. The year with the least shortfall is then recommended for the leave requested for. During the projection period, the algorithm developed in this work computes the shortfall of the leave seeker's staff category bearing in mind that the leave seeker might get promoted out of the staff category which he/she was when (i.e. the year) the algorithm started the projection. It is in this aspect that this work improves on [4].
The development of the algorithm followed iterative incremental process model. The requirements for the system were first drafted. The usecase diagram in Figure 1 shows those requirements.

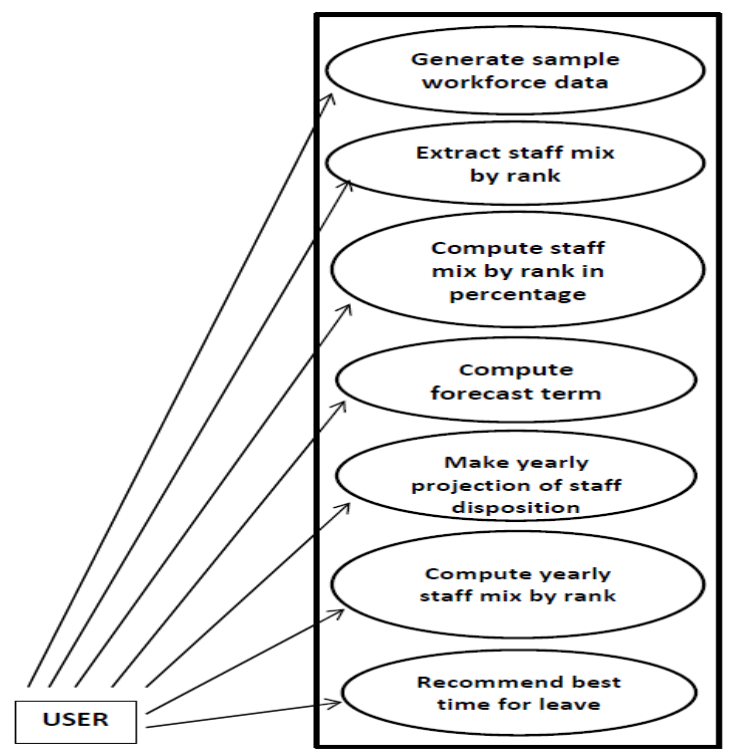

Figure 1: Usecase Diagram showing the Functionalities of the Leave Management Algorithm

These requirements were grouped into three, each forming an increment, i.e. three increments in all, as follows:

Increment 1 is required to generate sample workforce data, group the staff into their respective mix by rank and finally compute and display the staff mix by rank in number and in percentage. See Table I for staff mix by rank.

Increment 2 is required to make a year by year computation/projection of staff disposition for a certain number of years as defined by the compute year input by the user. In each of those years, the projected staff mix by rank, both in number and percentage, are computed, as well as the recommended staff mix by rank.

Table 1: Academic Staff Mix by Rank

\begin{tabular}{lllll}
\hline $\begin{array}{l}\text { S/N } \\
(r)\end{array}$ & $\begin{array}{l}\text { Ranks of } \\
\text { Academic staff }\end{array}$ & Categories & $\begin{array}{l}\text { Variable } \\
\text { Name }\end{array}$ & $\begin{array}{l}\text { Recommended staff mix by rank for } \\
\text { engineering (in percentage) }\end{array}$ \\
\hline 1. & $\begin{array}{l}\text { Graduate } \\
\text { Assistant }\end{array}$ & & \\
& $\begin{array}{l}\text { Assistant } \\
\text { 2. }\end{array}$ & Lecturer & L1-down & 45 \\
3. & Lecturer II (L II) & & \\
4. & Lecturer I (L 1) & & \\
5. & Senior Lecturer & Senior Lecturer & Snr-lect & 35 \\
6. & Associate & Professor/Associate & prof & 20 \\
7. & Professor & Professor & & \\
\hline
\end{tabular}


Increment 3 is required to make a year by year comparison of the required staff mix and projected staff mix, and sort for the year with the least difference which is recommended as best year for leave requested. This is in tandem with the prevalent situation in Nigeria universities where available lecturer-to-students ratio is less than recommended 1:15 for Engineering programs. The specific staff mix to be used for this comparison depends on the rank of the staff seeking leave.

\subsection{Increment 1 (Staff Data Generation and Classification):}

This increment was required to generate a sample workforce data; a given number of academic staff with the following details: Staff ID No., age, rank, time spent on current rank, Council for Regulation of Engineering in Nigeria (COREN) registration status, Masters and $\mathrm{PhD}$ certificates acquisition. Staff ID No. is a 3-digit unique identification number for each staff. Staff rank (r) is indicated as any of numbers 1 to 7; 1 - Graduate Assistant, 2 - Assistant Lecturer II, 3 - Lecturer II, 4 Lecturer I, 5 - Senior Lecturer, 6 - Associate Professor and 7 - Professor, as shown in Table I. For COREN registration, Masters and $\mathrm{PhD}$ status ' 1 ' was used to signify 'yes' and a ' 0 ' for nil status. Required also in this increment was the grouping of the workforce into the three categories shown in Table 1.

Next, is the extraction of staff mix by rank $z, y$, and $x$, and computation of staff mix in percentage: lecturer 1 and below ( $z 1)$, Senior lecturers ( $y 1)$, and Associate Professors and Professors ( $x 1)$. The algorithm for the development of this increment followed the design shown in Figure 2.

1 Input size of workforce

2 Input student number

3 Generate sample workforce data

4 Extract staff mix by rank $z, y$, and $x$

5 Compute staff mix by rank in percentage $z 1$, $y 1$, and $z 1$

6 Output staff mix by rank $z$, $y$, and $x$

7 Output staff mix by rank in percentage $z 1, y 1$, and $z 1$

Figure 2: Algorithm for staff data generation and classification

\subsection{Increment 2 (Staff Mix Projection):}

This increment basically makes a computation or projection of the status of academic staff (i.e. Staff ID number, age, rank, time spent on current rank, promotion and staff retiring) in a particular degree programme for a particular future year of interest. The implementation of this increment followed the algorithm shown in Figure 3. It begins with the input of projection-limit year, $t 2$, in the format YYYY, from which projection term, $t$, is computed. Projection term, $t$, is the difference between projection-limit year, $t 2$, and initial year (the zero point of the projection), $\mathrm{t}$. After this, a variable (1_y) is initialized to t1. This will be used in the third increment in sorting the year with the least shortfall (short). Since projection starts from the year after initial year, initial year is incremented by 1 to get the first projection year, t_next, which would be 2018 if the algorithm is run in 2017. Next, a counter is initialized to control the iteration of operations to be carried out on the staff disposition e.g. age and time spent on current rank, $t$, are incremented by 1 for every passing year. Rank is incremented by 1 , to reflect promotion, on the third year a staff spends on a rank. This is in accordance with NUC regulation that an academic staff is to spend a minimum of three years on a rank. Once rank is incremented, time spent on rank is reset to zero (0). The updated staff disposition, (i.e. that of 2018, following the example), is then displayed. From the updated disposition, staffs with age 70 or above are expunged from the workforce list. Disposition of staff still in service is then displayed. As done in increment 1 , staff mix by rank is computed for the current workforce. This 'current workforce', from this point of the leave management program, is referred to as 'projected staff mix by rank'. Also computed is the required staff mix by rank using the mathematical model formulated in [2] given as follows: Required No. of L1-down for a given engineering program,

$$
z_{4}=\frac{9 n}{300}
$$

Required No. of Senior Lecturers for a given engineering program,

$$
y_{4}=\frac{7 n}{300}
$$

Required No. of Professor/Associate Professor for a given engineering program,

$$
x_{4}=\frac{n}{75}
$$

Where $n$ is the number of students in a particular engineering program under consideration 
In tandem with the iterative incremental process model used in the work, increment 1 was then updated with increment 2 and tested.

\subsection{Increment 3 (Determination of Appropriate Time for Leave):}

Algorithm for increment 3 is shown in Figure 4. This increment implemented the third set of requirements which in effect are determination of best leave period by the comparison of the required/recommended staff mix by rank to projected staff mix by rank for each year of the projection term, and then picking the year with the least difference. Note that 'projected staff mix' here was previously called 'available staff mix' in the third paragraph of section 3.0. The only difference is that 'available staff mix' is staff mix at the start of the leave management algorithm while 'projected staff mix' refers staff mix that will be available down the years, assuming no fresh recruitments are made. Important in this computation is the rank of staff seeking leave. If the current rank $(r)$ of staff seeking leave falls in category 1 (i.e. L1-down), then the comparison will be between number of category 1 staff required and number of category 1 staff projected for that particular year. For the next year, the current rank of leave seeker is again extracted from the staff projected staff disposition of that year. This is to take care of possible change in rank due to promotion or demotion. This procedure is followed year by year until completion of the projection term. Recall from Table 1 that rank $(r)$ ranges from 1 to 4 for category 1 staff, 5 for category 2, and $6-7$ for category 3 staff.

Beginning from the input of the ID number of staff seeking leave, the current $\operatorname{rank}(r)$ of that staff is extracted from the current staff disposition. The next stage is making a decision of which variables to use for the comparison. First, is rank, $r \leq 4$ ? (i.e. does the staff seeking leave currently belong to category 1 in the staff mix?) If that condition is met, the algorithm computes shortfall (short) which is difference of required number in category $1(z 4)$ to projected number for category $1(z 2)$, and does essentially a bubble sort of this yearly difference, and picks the lowest value. The year corresponding to this value is recommended for the leave requested.

Decision node, Kount $\leq 2$ ?, is then evaluated as true since at this point counter, Kount, is 2 . A variable $N_{-}$old is assigned the value of short. In subsequent iterations, $N \_$old will hold the lowest value of previous computations of short, which is how bubble sort works. Next is the decision node $N_{-}$old $\leq$short? which compares current short with minimum of previous ones. If the condition is met, immediate past year of projection is picked as recommended leave year, leave_ $y r$. If it evaluates to false, leave_ $y r$ is assigned the current year of projection. Then as earlier stated, $N_{-}$old is assigned the minimum value of all short computations. The decision node, $(z 4-z) \leq N \_$old?, is next. Here, difference between of required number of category 1 staff (when the leave request was made), to the available number of category 1 staff is compared with $N_{-}$old. Note that $N_{-}$old at this point holds the value of minimum shortfall (short) for all the years of computation except the initial year (i.e. the zero point of the projection, $\mathrm{t} 1$ ). This is to make sure that the initial year, 11 , (year leave request was made) is considered in the sort for lowest value of short, because there is a possibility that the year the leave request is made (i.e. initial year) could be the best year for the leave, being the year with lowest value of shortfall (short). If decision node $(z 4-z) \leq N_{-}$old? evaluates to true, initial year, $t 1$, is recommended as best year for leave, otherwise the year having current value of $N_{-}$old as its shortfall is recommended instead. If the condition, $r \leq 4$ ?, were to evaluate to false, condition $r=5$ ? is checked to see if the staff seeking leave is currently in the Senior lecturers category (category 2). If true, the same process as executed when the condition $r \leq 4$ ? was met is executed. This time short will be difference between required number for category $2\left(y^{4}\right)$ and projected number of staff in category $2(y 2)$. If $r=5$ ? is false, then short will be difference between required number for category 3 $(x 4)$ and projected number of staff in category $3(x 2)$. Kount $\leq t$ ? is evaluated to see if projection has been made for all the years within the projection term. If all the years in the projection term has been covered, recommended year for leave is displayed else the process is restarted from just after the initialization of counter, Kount = 1, in Figure 3.

This work is actually the algorithm used for a leave management module, being a part of a human resource information system for Nigerian universities - a web application. The leave management module is developed as a request workflow where university staff can log on to make their leave request. The staff can monitor his request as it moves through the approval levels. 

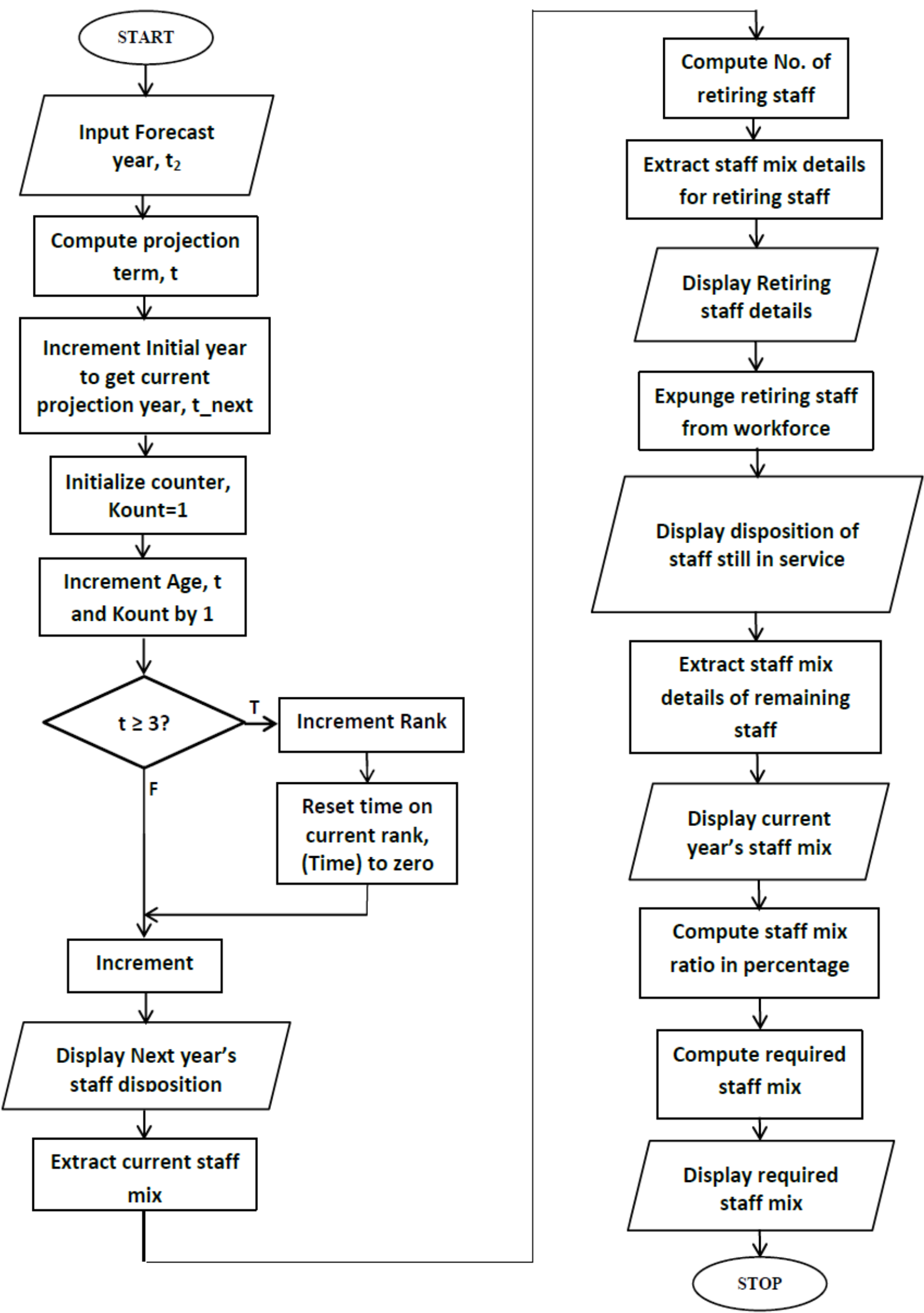

Figure 3: Algorithm for Increment 2 (Staff Mix Projection) 


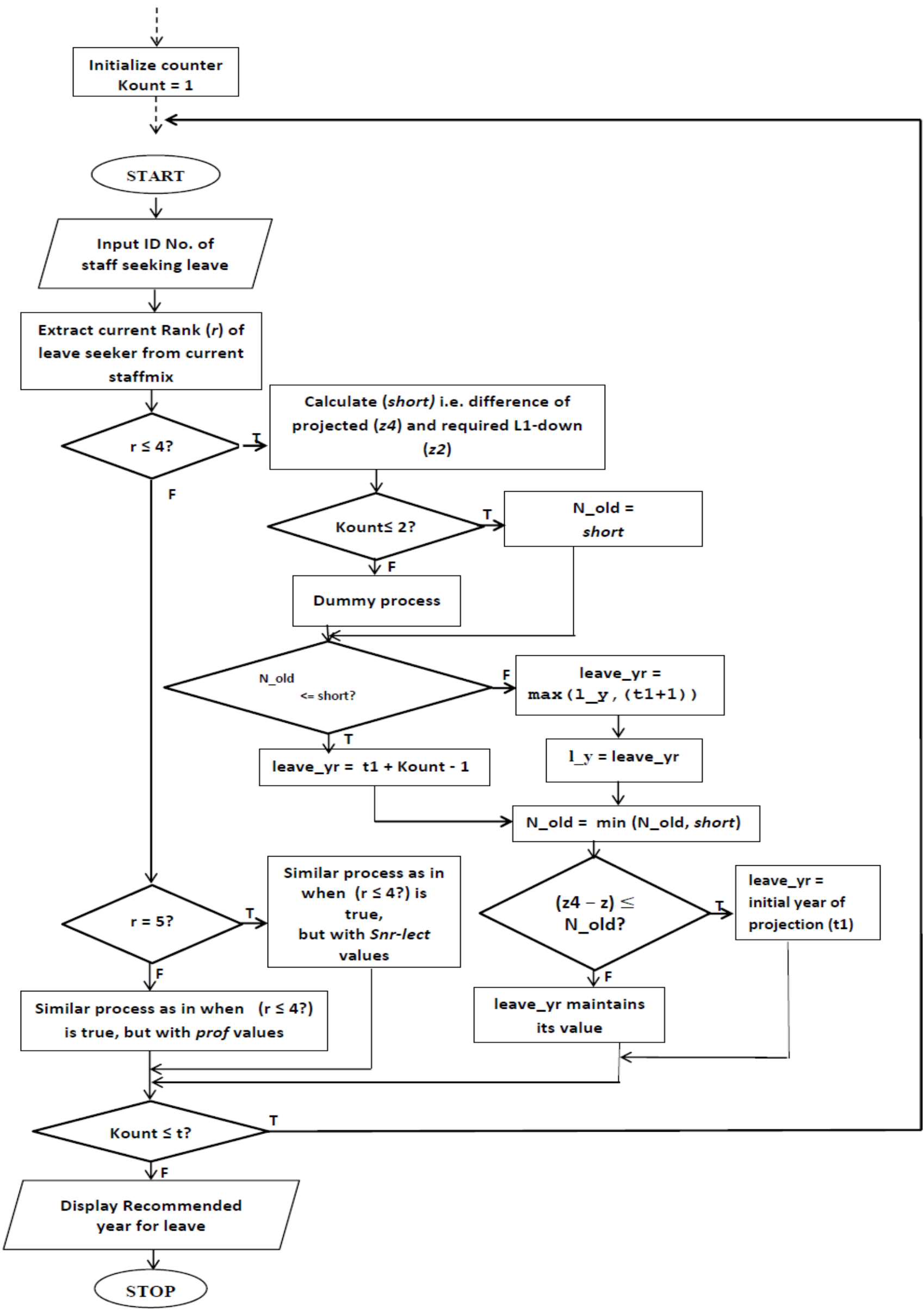

Figure 4: Algorithm for Increment 3 (Determination of Appropriate Time for Leave) 


\section{RESULTS AND DISCUSSION}

The algorithm was implemented using MATLAB 2010 version. The output from the execution of increment 1 is shown in Figure 5. With size of sample workforce input as 15, and student population at 400 , the program then displays 15 academic staff with their ranks, time spent on current rank (denoted as ToR), COREN, Masters in Engineering (M.Eng) and $\mathrm{PhD}$ status. The staff mix by rank is displayed at the foot of the screenshot.

Projected staff standing for the first projection year, i.e. the year after initial year, is displayed in the screenshot of Figure 6, after the input of 2021 as projection-limit year. Number of retiring staff is identified by the program as seen at the foot of the screenshot. Important is the ID number of staff seeking leave which in this run of the program was supplied as 465 . The staff with ID number 465 was picked since its rank will change within the projection term of three years (between 2018 and 2021). This was to assess the accuracy of the algorithm in recommending leave year taking into consideration staff promotion since it was designed to also interface with staff appraisal setup.

Shown in figure 7 is the 2019 current staff disposition after removal of the retiring staff. Also shown is the projected staff mix by rank and the required staff mix by rank for same 2019 .

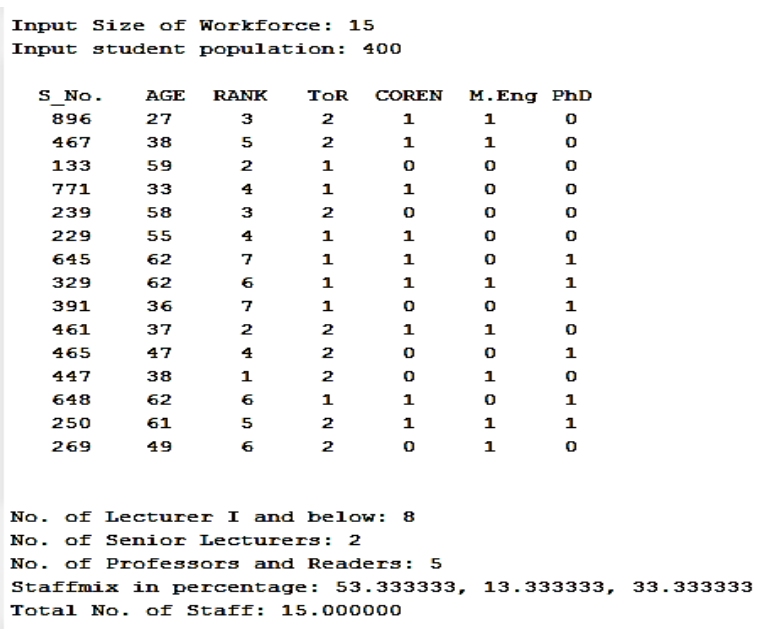

Figure 5: Screenshot showing from execution of increment 1

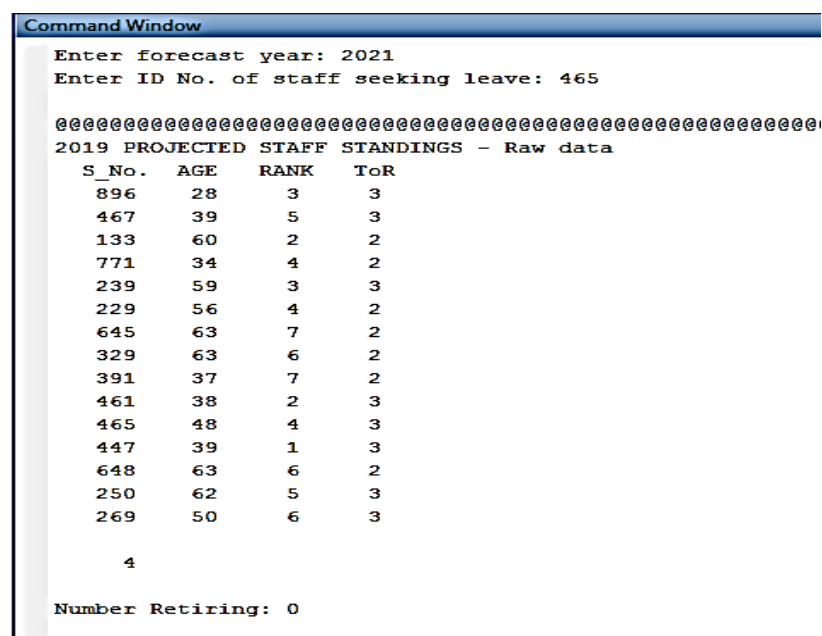

Figure 6: Screenshot showing projected staff standings for first projection year

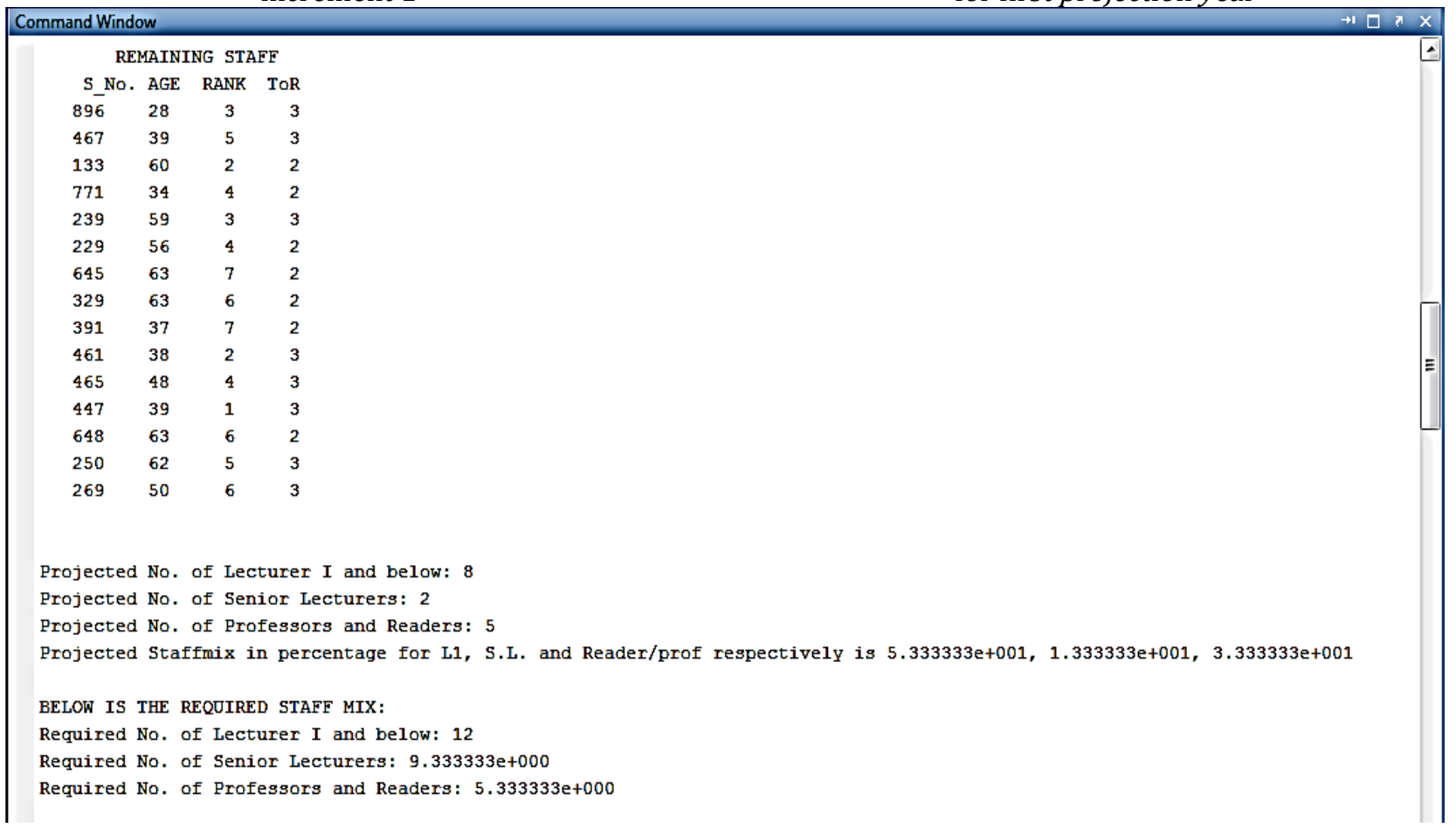

Figure 7: Screenshot showing Current staff standings 
Recall from Figure 6 that 2021 was input as the projection-limit year. The program can project and recommend leave periods for up to 20 years from the initial year. The screenshot in Figure 8 shows staff disposition for 2020, the second projection year.

The staff disposition, projected staff mix by rank and required staff mix by rank for the last year of projection, 2021, is shown in Figure 9. This screenshot ultimately displays the year, 2018, the program recommends for leave applied for by staff with ID no. 465 . The ' 0.2143 ' just above the recommended leave year is the highest of the ratios of projected or available to required category 1 staff in 2018 and 2019 (the period the staff was a category 1 staff); and ratios of projected or available to required category 2 staff in 2020 and 2021 (the period the staff was promoted into category 2 ).

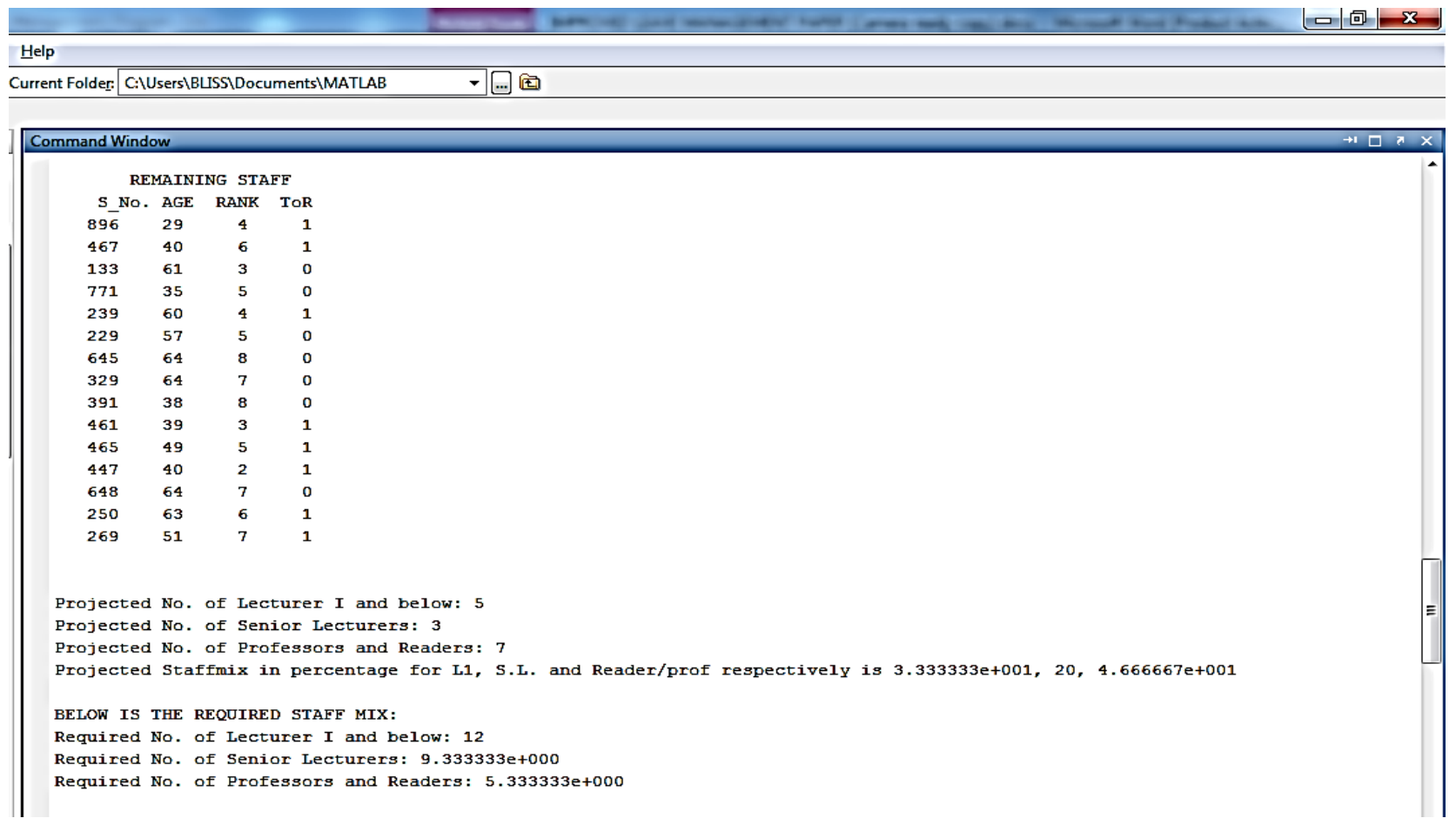

Figure 8: Screenshot capturing disposition of staff in service in the second projection year (2020)

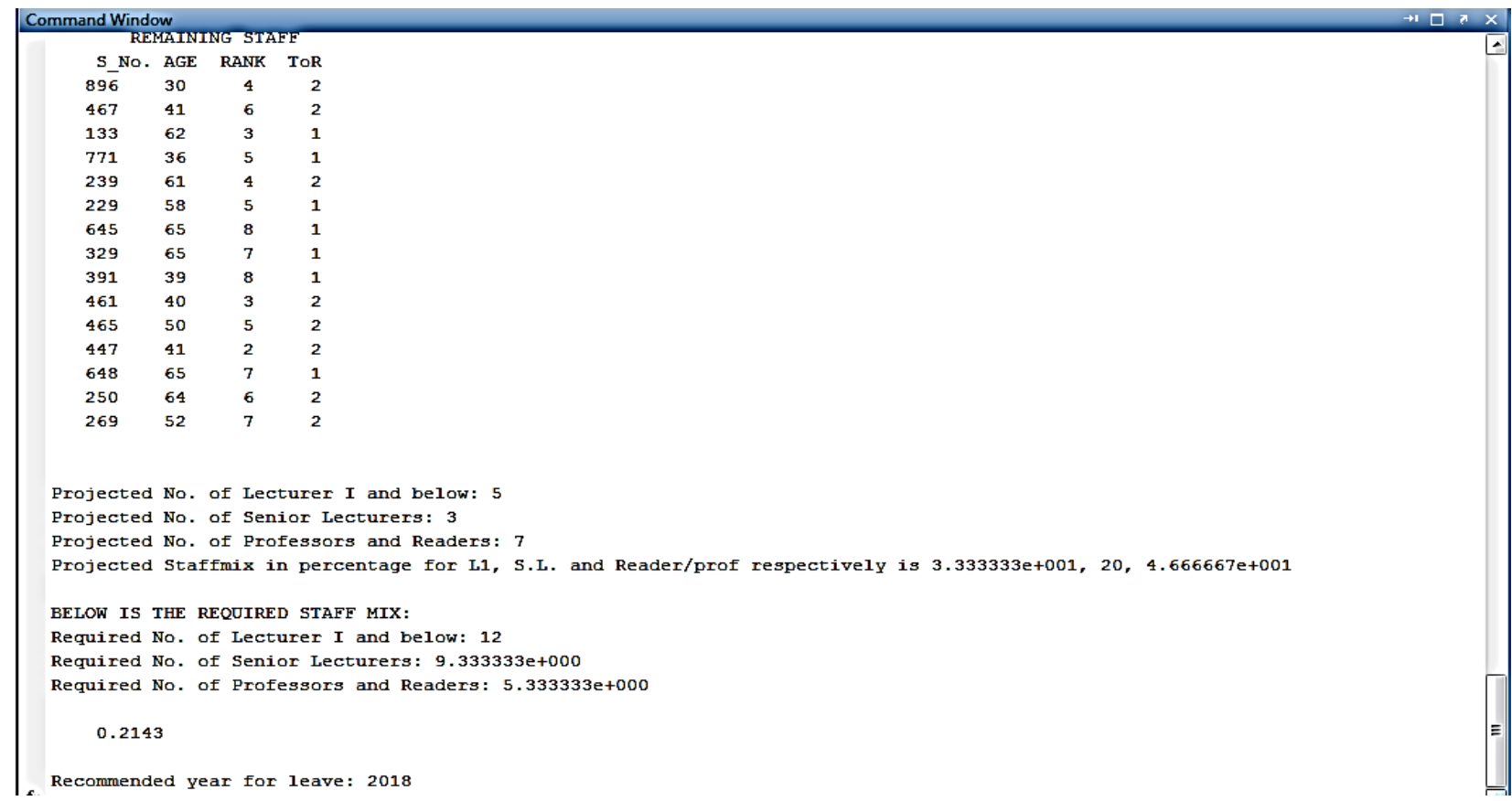

Figure 9: Screenshot showing recommended year for leave 


\section{CONCLUSION AND RECOMMENDATION}

The work has as features generation of sample data of academic staff in a particular engineering degree program, sorting of that data in the staff mix by rank, computation of available/projected and required/ recommended staff mix by rank given the number of students the engineering program has. Since the work aimed at scheduling leave for periods of least impact on service delivery of university academic staff, the lecturer-to-students ratio and staff mix by rank were used for decision on leave requests.

The system can be given the granularity of recommending best times for monthly leave requests instead of just annual leave requests.

\section{REFERENCES}

[1] R. A. Sagum, "Electronic human resource management adoption in the state universities of the Philipines," International journal of information technology and business management, Vol. 40, No. 1, pp. 39-46, 2015.

[2] Y. Tella and S. Daniel, "Mathematical Model for Nigerian University Academic Staff Mix by Rank,"
International Journal of Educational Planning \& Administration, Vol. 3, No. 2, pp. 145-150, 2013.

[3] S. Tkatek, O. Abdoun, and J. Abouchakaba, "An Expert System for a Constrained Mobility Management of Human Resources," 2017 International Colloquium on Logistics and Supply Chain Management (LOGISTIQUA), pp. 53 - 58, 2017.

[4] B. U. Stephen and G. A. Chukwudebe, "Leave management solution for improved service delivery in nigeria university system," ElectroTechnology for National Development (NIGERCON), IEEE 3rd International Conference, pp 606 - 611, 2017.

[5] B. M. Adeyemi and J. K. Agboola, "Projecting enrolment for effective academic staff planning in Nigerian universities," Educational planning, Vol. 21. No. 1.

[6] M. A. Aaron, https://www.linkedin.com/pulse/ impact-ict-human-resource-managementmulyanyuma-aaron-aaron. [Online]. [Cited: January 23, 2016.], 2015. 